Check for updates

Cite this: Phys. Chem. Chem. Phys., 2018, 20, 1181

Received 27th October 2017, Accepted 8th December 2017 DOI: $10.1039 / c 7 c p 07281 c$

rsc.li/pccp

\section{Theoretical study of non-Hammett vs. Hammett behaviour in the thermolysis and photolysis of arylchlorodiazirines $\dagger$}

\author{
Xing-Liang Peng, ${ }^{a}$ Annapaola Migani, (DD ${ }^{b}$ Quan-Song Li, *a Ze-Sheng Li (D) a and \\ Lluís Blancafort iD *c
}

\begin{abstract}
Arylchlorodiazirines (ACDA) are thermal and photochemical precursors of carbenes that form these molecules via nitrogen elimination. We have studied this reaction with multireference quantum chemical methods (CASSCF and CASPT2) for a series of ACDA derivatives with different substitution at the aromatic ring. The calculations explain the different reactivity trends found in the ground and excited state, with good correlation between the calculated barriers and the experimental reaction rates. The ground state mechanism can be described as a reverse cycloaddition with small charge transfer from the aromatic ring to the diazirine moiety. This is consistent with the lack of correlation between the Hammett $\sigma$ descriptors and the experimental rates. In contrast, the excited state reaction is the cleavage of a single $\mathrm{C}-\mathrm{N}$ bond mediated by small barriers of $4-6 \mathrm{kcal} \mathrm{mol}^{-1}$. The reaction path goes through a conical intersection with the ground state, which facilitates radiationless decay and explains the disappearance of the transient absorption signal measured experimentally. This leads to a diazomethane intermediate that ultimately yields the carbene. Electronically, excitation to $S_{1}$ is characterized initially by significant charge transfer from the phenyl ring to the diazirine. The charge transfer is reversed during the $\mathrm{C}-\mathrm{N}$ cleavage reaction, and this explains the preferential stabilization of the excited-state minimum by polar solvents and electron-donating substituents. Therefore, our calculations reproduce and explain the relationship found experimentally between the Hammett $\sigma^{+}$parameters and the life time of $\mathrm{S}_{1}$ (Y. L. Zhang, et al. J. Am. Chem. Soc., 2009, 131, 16652-16653).
\end{abstract}

\section{Introduction}

Understanding chemical reactivity is one of the main goals of theoretical chemistry. There are many methods to confront this task, with different levels of sophistication. However, our understanding of excited-state reactivity is much less advanced than that of ground-state (thermal) chemistry. Most recent developments in excited-state theoretical and computational chemistry have focused on improving the description of energetics and dynamics, while efforts to apply reactivity descriptors to the

\footnotetext{
${ }^{a}$ Beijing Key Laboratory of Photoelectronic/Electrophotonic Conversion Materials, Key Laboratory of Cluster Science of Ministry of Education, School of Chemistry and Chemical Engineering, Beijing Institute of Technology, 100081 Beijing, China. E-mail: liquansong@bit.edu.cn

${ }^{b}$ Departament de Química Biològica i Modelització Molecular, IQAC-CSIC, Jordi Girona 18-26, 08034 Barcelona, Spain

${ }^{c}$ Institut de Quimica Computacional i Catàlisi and Departament de Quimica, Universitat de Girona, Facultat de Ciències, C/M. A. Capmany 69, 17003 Girona, Spain. E-mail: lluis.blancafort@udg.edu

† Electronic supplementary information (ESI) available. See DOI: 10.1039/ c7cp07281c
}

excited state or developing specific excited-state descriptors have been scarce, in comparison. ${ }^{1-6}$ Surprisingly, the simple but very effective Hammett approach, which is mainly used to rationalize the ground-state reactivity of aromatic systems on the basis of the electron donating or accepting character of the ring substituents, has been used only in a few examples to rationalize photophysical ${ }^{7-12}$ or photochemical properties. ${ }^{13}$ In this paper we centre on one such case and show that state of the art quantum chemical methods reproduce the experimental trends and provide new insight into the molecular factors that determine the reactivity.

Our reaction of interest is the nitrogen elimination of arylchlorodiazirine (ACDA) derivatives (see Scheme 1) to yield arylchlorocarbenes. This reaction proceeds thermally and photochemically. Part of the reason for our interest is that this is one of only few excited state reactions where the Hammett approach has been applied, and that it follows different trends in the ground and excited state. For the ground state there is no clear correlation between the thermal reaction rates and the Hammett $\sigma$ descriptors. ${ }^{14}$ In contrast, the excitedstate reaction rates show an excellent Hammett correlation with 


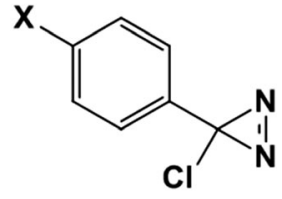

ACDA

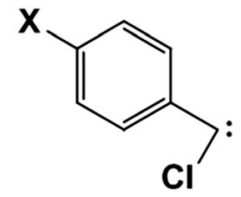

Carbene
$X=p-\mathrm{CH}_{3} \mathrm{O}$ $\mathrm{X}=p-\mathrm{CH}_{3}$ $\mathrm{X}=p-\mathrm{Cl}$ $\mathrm{X}=p-\mathrm{H}$ $\mathrm{X}=p-\mathrm{NO}_{2}$ $\mathrm{X}=m-\mathrm{Cl}$ $\mathrm{X}=p-\mathrm{CF}_{3}$
Scheme 1

the $\sigma_{\mathrm{p}}^{+}$descriptors of the aryl substituents, ${ }^{15}$ which reflect the ability of the substituents to stabilize a developing positive charge. ${ }^{16}$ To understand the difference between ground- and excited-state decomposition, we have carried out potential energy surface calculations combined with orbital and Mulliken charge analyses.

ACDA derivatives are also of fundamental interest in the context of diazirine and carbene chemistry. Diazirines are precursors of carbenes. ${ }^{17,18}$ They yield carbenes photochemically under mild conditions. ${ }^{19,20}$ Ultrafast time-resolved laser flash photolysis of aryl diazo compounds $\mathrm{s}^{21-23}$ and aryldiazirines ${ }^{24-26}$ has provided valuable information on the dynamics of the precursor excited states and the generated singlet arylcarbenes. Using ultrafast infrared spectroscopy, the singlet aryldiazomethane and arylcarbene intermediates were detected in the photolysis of phenyldiazirine, phenylchlorodiazirine and $p$-methoxy-3-phenyl-3-methyldiazirine in less than 1 ps upon excitation. ${ }^{25}$ The linear diazo isomers are interpreted as intermediates in the photolysis to carbenes. ${ }^{26}$ In fact, the excited states of aryl diazo compounds typically decay within $300 \mathrm{fs}$ to form singlet aryl carbenes. ${ }^{22,23,27-29}$ This supports the idea that diazirines photoisomerize to diazo compounds and subsequently fragment to form carbenes in a stepwise fashion. ${ }^{19,30-32}$

The photodecomposition of diazirine has been studied also theoretically, ${ }^{33-40}$ and the more recent theoretical calculations favor the stepwise excited-state mechanism. The ground and excited states of both $3 H$-diazirine and diazomethane were studied with the complete active space second order perturbation (CASPT2) and complete active space self consistent field (CASSCF) methods, ${ }^{41}$ CASPT2//CASSCF, and it was proposed that the carbene is formed on the ground-state surface after decay of excited diazirine through a conical intersection, leading to diazomethane formation. The lowest singlet excited states of phenyldiazirine and phenyldiazomethane were also studied at the time-dependent (TD) density functional theory (DFT) level with the B3LYP functional, TD-B3LYP/6-31+G(d), and with restriction of identity (RI) coupled cluster (CC), RI-CC2/TZVP. ${ }^{32}$ It was found that in the ground state, direct formation of phenylcarbene from phenyldiazirine is favored along with the release of nitrogen, while on the excited state the stepwise path is preferred, i.e. isomerization into phenyldiazomethane followed by formation of phenylcarbene.

Turning to our system of interest, ACDA, its ground- and excited state decomposition to yield carbenes has been studied experimentally for a series of derivatives with different aryl ring substitution (see Scheme 1, where $p$ and $m$ refer to substitution

on the para and meta positions). The lack of a Hammett correlation for the thermolysis reaction rates was explained arguing that the mechanism involved structures with mixed diradical/zwitterionic character. ${ }^{14}$ This contrasts with the results for the photolysis of several ring-substituted analogues, which was studied with ultrafast spectroscopy in different solvents (acetonitrile, chloroform and cyclohexane) by Zhang et al. ${ }^{15}$ In this case the first excited state $\left(\mathrm{S}_{1}\right)$ lifetimes of ACDA increase with solvent polarity and the electron-donating ability of X substituents, and excellent Hammett correlations between $\mathrm{S}_{1}$ state lifetimes and the substituent constants $\left(\sigma_{\mathrm{p}}^{+}\right)$were established. This was interpreted in terms of a dipolar intermediate, which was confirmed by TD-DFT and RI-CC2 calculations. ${ }^{32}$ In our study, we use mutireference methods (CASSCF and CASPT2) to reproduce the reactivity trends in the ground and excited states and extract the molecular details that explain the different behaviors. In the ground state, there is only a small amount of charge transfer from the ring to the diazirine, consistent with the lack of a Hammett correlation. In contrast, the excitation induces initially a substantial intramolecular charge transfer to the ring; during the $\mathrm{C}-\mathrm{N}$ cleavage reaction, the charge transfer is reversed, and this explains the stabilization of the $S_{1}$ species by polar solvents and electron donating substituents on the ring.

\section{Computational details}

The calculations were carried out with the CASPT2//CASSCF approach, where the geometries of critical points, i.e. ground and first singlet excited state minima and transition structures, $\left(\mathrm{S}_{0}\right)$-Min, $\left(\mathrm{S}_{1}\right)$-Min, $\left(\mathrm{S}_{0}\right)$-TS and $\left(\mathrm{S}_{1}\right)$-TS, and $\mathrm{S}_{1} / \mathrm{S}_{0}$ conical intersection $\left(\mathrm{S}_{1} / \mathrm{S}_{0}\right)$-X, were optimized at the CASSCF level (the geometries and selected bond lengths are shown in Fig. 1), and the energies recalculated at the CASPT2 level to account for dynamic correlation. Excited-state optimizations were carried out state-averaging over $S_{1}$ and $S_{0}$ with equal weights and the TSs were characterized with numerical frequency calculations. The 6-31G* and ANO-S basis sets (contraction scheme 3s2p1d for all atoms except $2 \mathrm{~s} 1 \mathrm{p}$ for $\mathrm{H}$ ) were used for CASSCF and CASPT2 calculations, respectively. The CASSCF and TD-CAMB3LYP/6-31G* calculations were carried out with the Gaussian $03^{42}$ and Gaussian 09 packages, ${ }^{43}$ and the CASPT2 ones with Molcas 8.0 software. $^{44}$

The complete active space of $p$-H-ACDA at $\left(\mathrm{S}_{0}\right)$-Min, which has $C_{\mathrm{s}}$ symmetry (see Fig. 1 for the structure and atomic labelling), is 14 electrons in 13 orbitals. This comprises four occupied and four unoccupied $\pi$ orbitals of $a^{\prime \prime}$ symmetry resulting from combination of the benzene $\pi$ orbitals and two orbitals localized on the $\mathrm{C}_{12}-\mathrm{N}_{14}$ and $\mathrm{C}_{12}-\mathrm{N}_{15}$ bonds; two $\pi$ orbitals of the $\mathrm{N}=\mathrm{N}$ bond (labelled as $\pi_{\mathrm{N}=\mathrm{N}}$ and $\pi_{\mathrm{N}}=\mathrm{N}^{*}$ ), of $\mathrm{a}^{\prime}$ and a" symmetry; two $\sigma$ orbitals localized on the $\mathrm{C}_{12}-\mathrm{N}_{14}$ and $\mathrm{C}_{12}-\mathrm{N}_{15}$ bonds (of a' symmetry); and the $3 \mathrm{p}$ orbital of $\mathrm{Cl}$. This orbital was not included in the final active space because its electron occupation number in test calculations is almost 2.0. The resulting $(12,12)$ active space $(12$ electrons in 12 orbitals) 


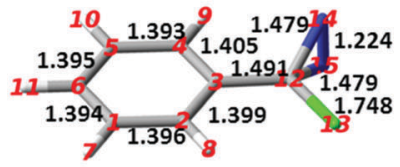

a $\left(\mathrm{S}_{0}\right)-\mathrm{Min}$

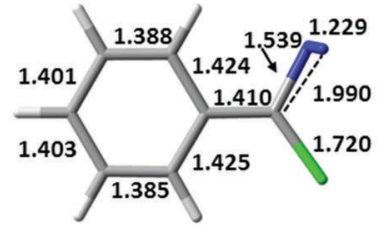

$d\left(S_{1}\right)-T S$

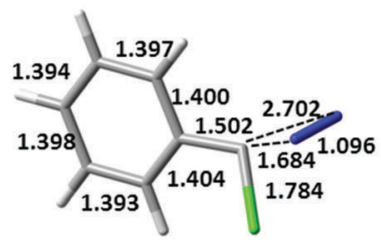

$\mathbf{g}\left(\mathrm{S}_{0}\right)-\mathrm{TS}^{\prime}$

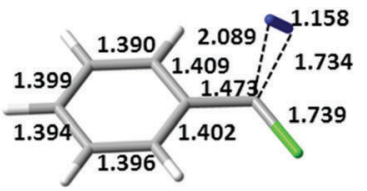

b $\left(\mathrm{S}_{0}\right)-\mathrm{TS}$

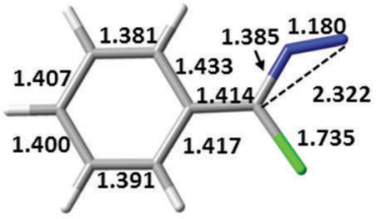

e $\left(\mathrm{S}_{1} / \mathrm{S}_{0}\right)-\mathrm{X}$

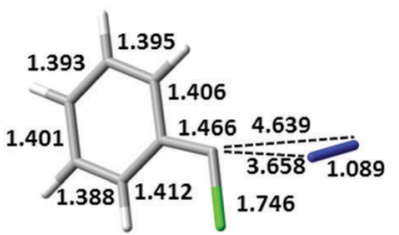

$\mathrm{h}\left(\mathrm{S}_{0}\right)$-carbene

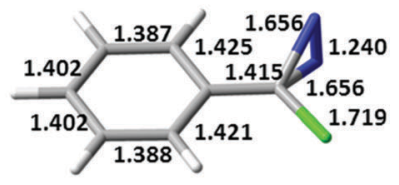

c $\left(S_{1}\right)$-Min

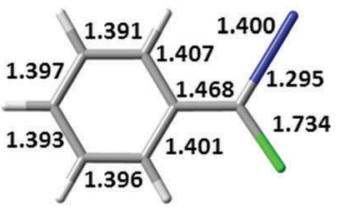

$f\left(S_{0}\right)$-diazo

Fig. 1 The critical structures of $p-\mathrm{H}-\mathrm{ACDA}$.

for $p$-H-ACDA is shown in Fig. 2. An analogous active space was used for the remaining derivatives (see Tables ESI3-ESI7 in the ESI $\dagger$ ). This active space choice provides a balanced description of the excited state and ground state because the energy degeneracy at $\left(\mathrm{S}_{1} / \mathrm{S}_{0}\right)$-X optimized at the CASSCF level is kept at the CASPT2 level within $0.1 \mathrm{eV}$, which validates the choice. The CASPT2 energies of optimized critical points were calculated averaging over three states with equal weights except for the vertical excitations at $\left(\mathrm{S}_{0}\right)$-Min with five states. An IPEA ${ }^{45}$ parameter of 0.0 and an imaginary level shift ${ }^{46}$ of 0.1 were used in all CASPT2 calculations.

The barriers provided in Tables 1 and 3 correspond to free energy barriers including the zero-point energy (ZPE) correction. Because of the large active spaces, the state-averaged CASSCF optimizations do not include the orbital rotation contributions to the gradients. ${ }^{47}$ This renders the CASSCF calculation of the ZPE unreliable. For this reason, the ZPE at $\left(\mathrm{S}_{0}\right)$-TS and $\left(\mathrm{S}_{1}\right)$-TS
Table 1 Calculated free energy barriers $\left(\Delta G_{\text {rel }}\right)$ for thermal decomposition of $p$-R-ACDA derivatives in cyclohexane, relative amount of charge transferred from the aromatic ring to the diazirine at the TS $(\Delta q)$, and experimental rate constants measured at $75^{\circ} \mathrm{C}$ in cyclohexene $e^{14}$

\begin{tabular}{lllll}
\hline & & \multicolumn{2}{l}{$\frac{\Delta q^{b}[\text { a.u. }]}{}$} & \\
\cline { 3 - 4 }$R$ & $\Delta G_{\text {rel }}{ }^{a}\left[\mathrm{kcal} \mathrm{mol}^{-1}\right]$ & Mull. & TFVC $^{d}$ & $k_{\text {dec }}\left[10^{-4} \mathrm{~s}^{-1}\right]$ \\
\hline$p-\mathrm{CH}_{3} \mathrm{O}$ & 25.1 & -0.07 & -0.05 & 6.2 \\
$p-\mathrm{CH}_{3}$ & 27.9 & -0.05 & -0.06 & 2.91 \\
$p-\mathrm{Cl}$ & 28.4 & -0.04 & -0.05 & 2.48 \\
$p-\mathrm{H}$ & 28.4 & -0.03 & -0.06 & 1.95 \\
$p-\mathrm{NO}_{2}$ & 28.6 & -0.03 & -0.02 & 2.04
\end{tabular}

${ }^{a}$ CASPT2//CASSCF including solvent and ZPE correction, see Computational details. ${ }^{b}$ Difference between $\mathrm{C}_{12}, \mathrm{~N}_{14}$ and $\mathrm{N}_{15}$ atomic charges at $\left(\mathrm{S}_{0}\right)$-Min and $\left(\mathrm{S}_{0}\right)$-TS $\left(q^{\mathrm{TS}}-q^{\mathrm{Min}}\right)$ in vacuum. ${ }^{c}$ Charges obtained from Mulliken analysis. ${ }^{d}$ Charges obtained from TFVC analysis (see Computational details).
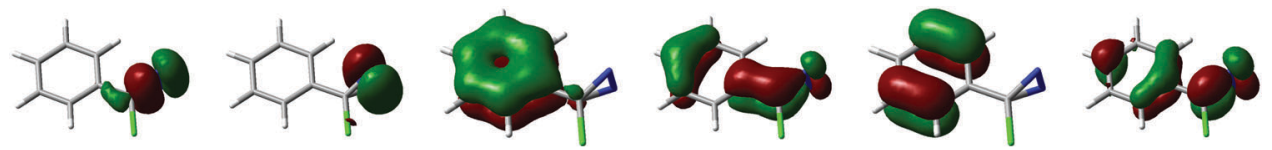

$\sigma_{1}$
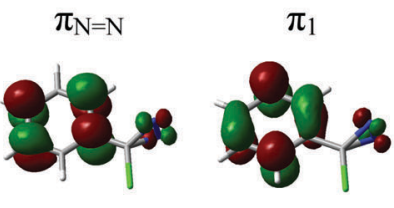

$\pi_{\mathrm{N}=\mathrm{N}}^{*}$

$\pi_{5}$

$\pi_{6}$

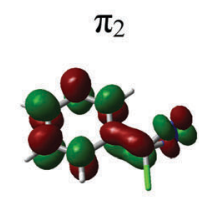

$\pi_{7}$
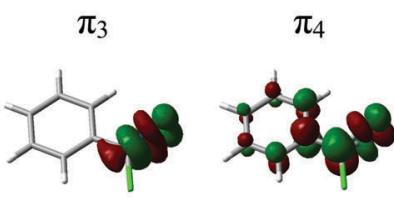

$\sigma_{2}$

$\pi_{8}$

Fig. 2 CASSCF Active space orbitals at $p-H-A C D A\left(S_{0}\right)-M i n$. 
was obtained at the CAM-B3LYP and TD-CAM-B3LYP level, respectively, and the values in Tables 1 and 3 correspond to CASPT2//CASSCF energies with TD-CAM-B3LYP ZPE correction. The calculations in the solvent of interest (cyclohexane for the ground state and acetonitrile for the excited state) were carried out using the cavity-based reaction-field polarizable continuum model $(\mathrm{PCM})^{48}$ both for the CASSCF optimizations and the CASPT2 single-points.

The atomic charges presented in Tables 1 and 3 were obtained with a Hilbert-space and a real-space approach to validate that the conclusions are independent from the method used to obtain the charges. The methods of choice are Mulliken population (Tables ESI1 and ESI2, ESI $\dagger$ ) and topological fuzzy Voronoi cells (TFVC) (Table ESI3, ESI $\dagger$ ). ${ }^{49}$ The TFVC method is a computationally efficient real-space partition approach that gives similar results to the quantum theory of molecules in atoms. ${ }^{50}$

\section{Results}

\section{Ground-state reactivity}

The ground-state reactivity in cyclohexane has been calculated for the five derivatives for which the experimentally rates are available (see Table 1$).{ }^{14}$ The stationary structures of $p$-H-ACDA are shown as an example in Fig. 1 along with the selected bond parameters. $\left(\mathrm{S}_{0}\right)$-Min (Fig. 1a) has $C_{\mathrm{s}}$ symmetry with the $\mathrm{N}-\mathrm{N}$ bond perpendicular to the hexatomic ring plane, and the $\mathrm{C}-\mathrm{N}$ and $\mathrm{N}=\mathrm{N}$ bond lengths are 1.479 and $1.224 \AA$. These values agree with previous RI-CC2 results of 1.468 and $1.274 \AA^{15}{ }^{15}$ The structures or the remaining derivatives are shown in the ESI $\dagger$ (Fig. ESI1-ESI6). The structural differences with respect to the parent compound are small.

The calculated barriers for thermal decomposition of the ACDA derivatives are provided in Table 1 together with the experimental rate constants. They range from 25 to $29 \mathrm{kcal} \mathrm{mol}^{-1}$, approximately, and there is a good correlation between the calculated barriers and $\log (k)$, with $R^{2}=0.94$ (see Fig. ESI7, ESI $\dagger$ ). The formation of the carbene is endothermic by 9-14 kcal mol${ }^{-1}$ (see Table ESI3, ESI $\dagger$ ). The mechanism corresponds to an asynchronous, one-step nitrogen elimination reaction with the diazirine C-N bonds stretched to approximately 1.732 and $2.091 \AA$ (see Fig. $1 \mathrm{~b}$ and Fig. ESI1-ESI6, ESI $\dagger$ for the remaining derivatives).
This is in agreement with previous calculations on phenyldiazirine $^{32}$ and phenylchlorodiazirine. ${ }^{51}$ Analysis of the atomic charges shows that at $\left(\mathrm{S}_{0}\right)$-TS there is only a small charge transfer from the ring to the diazo moiety compared to $\left(\mathrm{S}_{0}\right)$-Min, of less than 0.1 electron computed either with Mulliken or TFVC analysis (see the $\Delta q$ values in Table 1). This explains the lack of a correlation between the Hammett substituent parameters and the thermal decomposition rate. ${ }^{14}$ It is also consistent with the description of the thermal decomposition as the reverse of a carbene attack on a nitrogen molecule, ${ }^{32}$ which would correspond to an asynchronous $[1+2]$ cycloaddition.

\section{Excited-state reactivity}

Vertical excitation energies. The excited-state reactivity was modelled for the six derivatives studied in the photolysis experiments. ${ }^{8}$ The vertical excitations of the parent derivative $p$-H-ACDA, calculated at the CASPT2/ANO-S level in acetonitrile, are presented in Table 2. TD-CAMB3LYP/6-311G** data are presented for comparison, and the data for the remaining compounds are provided in Tables ESI4-ESI8, ESI. $\dagger$ The $\mathrm{S}_{1}$ state appears at $3.35 \mathrm{eV}(370 \mathrm{~nm})$ at the CASPT2 level, in good agreement with the value of $369 \mathrm{~nm}$ observed experimentally in acetonitrile. ${ }^{15}$ It corresponds to a one-electron $\pi \rightarrow \pi^{*}$ excitation from a $\pi$ orbital delocalized over the whole molecule to a $\pi^{*}$ orbital of the $\mathrm{N}=\mathrm{N}$ bond orthogonal to the plane. The small overlap between the two orbitals causes the small oscillator strength of 0.005 . TD-CAMB3LYP provides similar results of $3.36 \mathrm{eV}$ and oscillator strength 0.004 . Importantly, the excitation features a partial intramolecular charge transfer (CT) from the phenyl ring to the diazirine nitrogen atoms (see the orbitals involved in the transition in Fig. 2). This can be also recognized from the increase in the dipole moment from 3.10 Debye at the ground state to 5.72 Debye in $S_{1}$, and by an increase in the negative charge of the two diazirine nitrogens of 0.10 per atom, as measured from the Mulliken charges (see Table ESI2, ESI $\dagger$ ). The remaining derivatives show similar $S_{1}$ excitation energies of 3.17-3.42 eV (see Tables ESI4-ESI8, ESI $\dagger$ ) and a similar charge shift to the diazirine ring (see Table ESI2, ESI $\dagger$ ). The higher-lying states appear, for all derivatives, at about $1 \mathrm{eV}$ higher than $S_{1}$ at the CASPT2 level. Given that the ultrafast photolysis measurements were initiated with $375 \mathrm{~nm}$ excitation, ${ }^{15}$ one can assume that the photolysis involves only the $S_{1}$ state.

Table 2 CASPT2/ANO-S and TD-CAM-B3LYP/6-311G** vertical excitations of $p-H-A C D A$ calculated in acetonitrile (PCM model) at ( $\left.\mathrm{S}_{0}\right)-\mathrm{Min}$ along with the main configurations (related orbitals are shown in Fig. 1), vertical excitation energies (excitation wavelength), oscillator strengths $(f)$ and dipole moments $(\mu)$

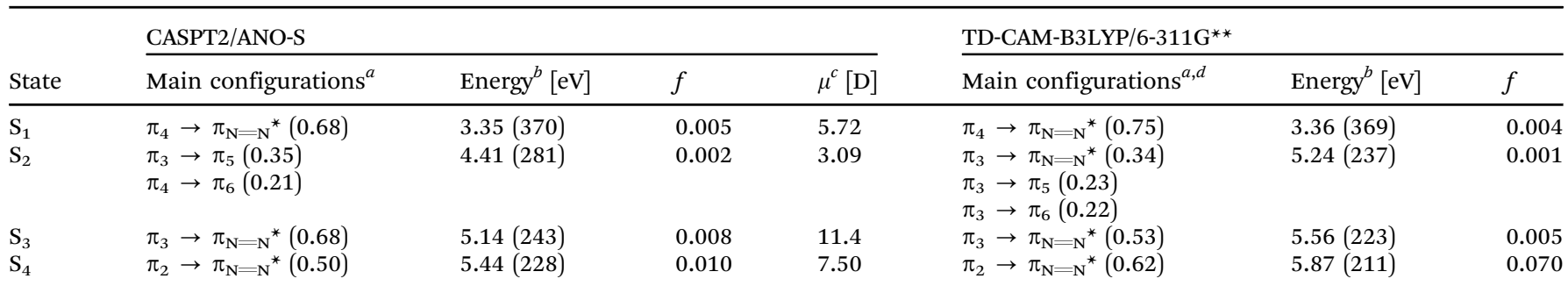

${ }^{a}$ Transition contribution of leading configurations. ${ }^{b}$ Transition wave length [nm] in parentheses. ${ }^{c}$ Ground-state dipole moment 3.10. ${ }^{d}$ See ESI for the CAM-B3LYP orbitals, Fig. ESI8. 
Table 3 Calculated free energy barriers for photolytic decomposition of R-ACDA derivatives in vacuum and acetonitrile $\left(\Delta G_{\mathrm{rel}}^{\mathrm{vac}} \text { and } \Delta G_{\mathrm{rel}}^{\mathrm{ACN}}\right)^{\mathrm{a}}$, relative amount of charge transferred from the aromatic ring to the diazirine at $\left(\mathrm{S}_{1}\right)$-Min and $\left(\mathrm{S}_{1}\right)-\mathrm{TS}\left(\Delta q^{\mathrm{Min}}\right.$ and $\left.\Delta q^{\mathrm{TS}}\right)$, experimental $\mathrm{S}_{1}$ life times measured in acetonitrile [ref. 8] and Hammett $\sigma^{+}$descriptors for the aryl substituents

\begin{tabular}{|c|c|c|c|c|c|c|c|c|}
\hline \multirow[b]{2}{*}{$R$} & \multirow[b]{2}{*}{$\Delta G_{\mathrm{rel}}^{\mathrm{vac}}\left[\mathrm{kcal} \mathrm{mol}{ }^{-1}\right]$} & \multirow[b]{2}{*}{$\Delta G_{\mathrm{rel}}^{\mathrm{vac}}\left[\mathrm{kcal} \mathrm{mol}^{-1}\right]$} & \multicolumn{2}{|c|}{$\Delta q^{\operatorname{Min} b}$ [a.u.] } & \multicolumn{2}{|c|}{$\Delta q^{\mathrm{TS} c}$ [a.u.] } & \multirow[b]{2}{*}{$\log \tau^{f}$} & \multirow[b]{2}{*}{$\sigma^{+g}$} \\
\hline & & & Mull. ${ }^{d}$ & $\mathrm{TFVC}^{e}$ & Mull. $^{d}$ & TFVC $^{e}$ & & \\
\hline$p-\mathrm{CF}_{3}$ & 3.8 & 4.0 & -0.16 & -0.25 & -0.08 & -0.19 & 1.03 & 0.53 \\
\hline$m-\mathrm{Cl}$ & 4.4 & 4.6 & -0.16 & -0.25 & -0.08 & -0.19 & 1.34 & 0.37 \\
\hline$p$-Cl & 4.6 & 4.8 & -0.17 & -0.25 & -0.09 & -0.19 & 1.70 & 0.11 \\
\hline$p-\mathrm{H}$ & 4.7 & 5.1 & -0.17 & -0.26 & -0.09 & -0.19 & 1.79 & 0.00 \\
\hline$p-\mathrm{CH}_{3}$ & 5.1 & 5.6 & -0.18 & -0.26 & -0.09 & -0.20 & 2.18 & -0.31 \\
\hline$p-\mathrm{CH}_{3} \mathrm{O}$ & 5.9 & 6.3 & -0.18 & -0.26 & -0.09 & -0.19 & 2.88 & -0.78 \\
\hline
\end{tabular}

${ }^{a}$ CASPT2//CASSCF including ZPE correction, see Computational details. ${ }^{b}$ Difference between $\mathrm{C}_{12}, \mathrm{~N}_{14}$ and $\mathrm{N}_{15}$ atomic charges at $\left(\mathrm{S}_{0}\right)$-Min (ground state) and $\left(\mathrm{S}_{1}\right)$-Min (excited state) $\left(q^{\mathrm{S}_{1} \text {-Min }}-q^{\mathrm{S}_{0} \text {-Min }}\right)$ in vacuum (see Table ESI2). ${ }^{c}$ Difference between $\mathrm{C}_{12}, \mathrm{~N}_{14}$ and $\mathrm{N}_{15}$ atomic charges at $\left(\mathrm{S}_{0}\right)$-Min (ground state) and ( $\left.\mathrm{S}_{1}\right)$-TS (excited state) $\left(q^{\mathrm{S}_{1} \text {-TS }}-q^{\mathrm{S}_{0}-\mathrm{Min}}\right)$ in vacuum. ${ }^{d}$ Charges obtained from Mulliken analysis. ${ }^{e}$ Charges obtained from TFVC analysis. ${ }^{f}$ Life times in $10^{-12}$ s. ${ }^{g}$ Ref. 56 and 57.

Calculations of $S_{2}$ at the critical points along the photolysis path support this assumption. In line with previous studies, ${ }^{31}$ we have also not considered triplet states in our calculations because intersystem crossing seems unlikely in the short excited-state times measured experimentally. The good agreement found between the experimental data and our results support these assumptions.

$\mathbf{S}_{1}$ reactivity. The excited-state photolysis has been calculated in vacuum and acetonitrile. It follows a different mechanism than the ground-state, as shown in Fig. 3. The excited-state reaction path involves decay to a reactant-like minimum, $\left(\mathrm{S}_{1}\right)$-Min, where the $\mathrm{CN}$ diazirine bonds are stretched to $1.656 \AA$ (see Fig. 1c). This species was detected experimentally as a transient with a broad absorption around $625 \mathrm{~nm}(2.0 \mathrm{eV})$ in the life time measurements. ${ }^{8}$ Our calculations support this assignment and suggest that the transient corresponds to an $\mathrm{S}_{1} \rightarrow \mathrm{S}_{3}$ absorption, which is calculated at $2.12 \mathrm{eV}$ with an oscillator strength 0.020 . The stretched diazirine ring at $\left(\mathrm{S}_{1}\right)$-Min was also found in previous computations on arylchlorodiazirines and other diazirines. ${ }^{15,26,34,35,41}$ The decay is followed by passage through $\left(\mathrm{S}_{1}\right)$-TS where a single diazirine $\mathrm{CN}$ bond is cleaved. The barrier relative to $\left(\mathrm{S}_{1}\right)$-Min for $p$-H-ACDA is $4.7 \mathrm{kcal} \mathrm{mol}^{-1}$, and the $\mathrm{C}-\mathrm{N}$ bond lengths are 1.539 and $1.990 \AA$. The concerted path involving synchronous cleavage of the two $\mathrm{C}-\mathrm{N}$ bonds was discarded because the barriers are $8-11 \mathrm{kcal} \mathrm{mol}^{-1}$ higher (see Table ESI10, ESI†).

The path continues to an open-ring, diazomethane like structure. This structure is a conical intersection with the ground state, $\left(\mathrm{S}_{1} / \mathrm{S}_{0}\right)-\mathrm{X}$. The presence of the intersection explains the disappearance of the transient absorption signal in the experiments, ${ }^{32}$ since it provides a way for the molecule to deactivate to the ground state. $\left(\mathrm{S}_{1} / \mathrm{S}_{0}\right)-\mathrm{X}$ has a planar structure with a bent $\mathrm{C}-\mathrm{N}-\mathrm{N}$ moiety. Such a bent $\mathrm{C}-\mathrm{N}-\mathrm{N}$ group at the conical intersection is characteristic of the conical intersections

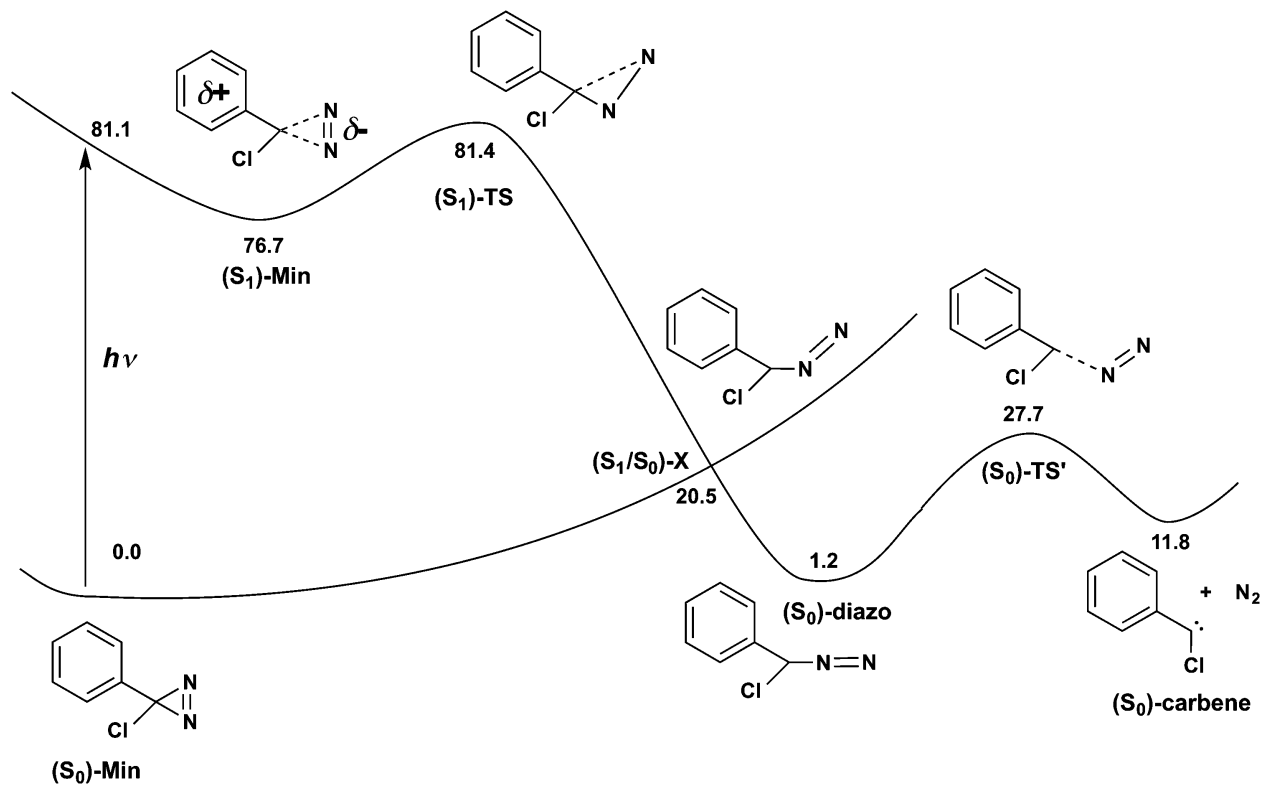

Fig. 3 Schematic representation of the excited-state reactivity of $p-\mathrm{H}-\mathrm{ACDA}$, showing cleavage of a $\mathrm{C}-\mathrm{N}$ diazirine bond to yield phenylchlorodiazomethane and further evolution to phenylcarbene. Numbers represent CASPT2//CASSCF energy in vacuum in kcal mol ${ }^{-1}$. 


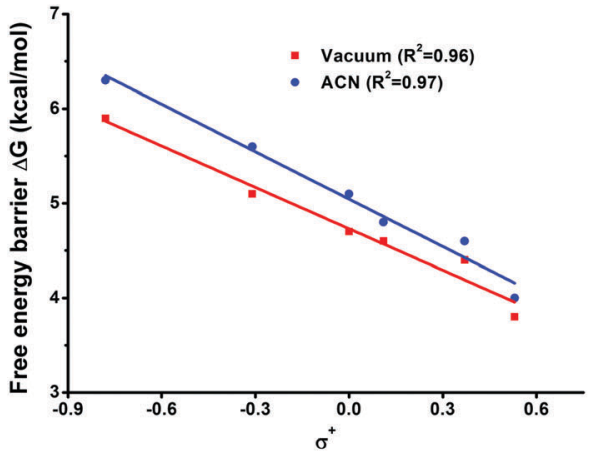

a

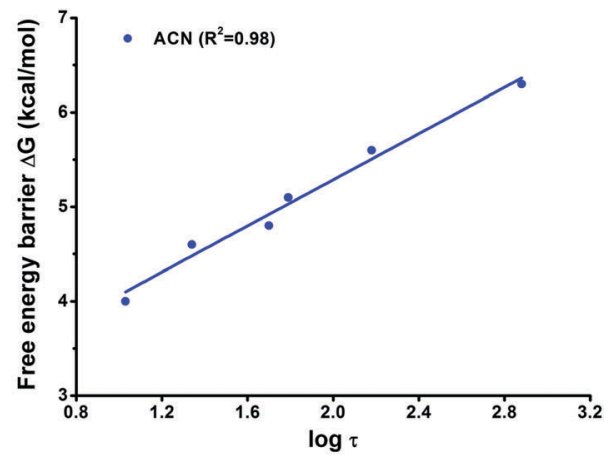

b

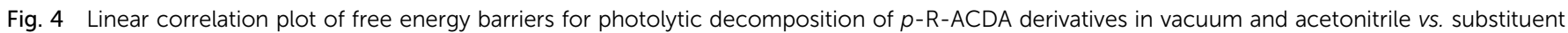

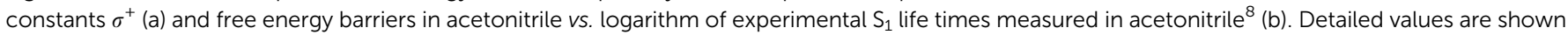
in Table 3.

found for other diazo compounds ${ }^{52,53}$ and azides. ${ }^{54,55}$ Analysis of the surface topology near the intersection shows that the crossing is connected to a single ground-state minimum (see Fig. ESI9, ESI $\dagger$ for details). This structure is the aryl, chlorodiazomethane minimum with a linear $\mathrm{C}-\mathrm{N}-\mathrm{N}$ group, as confirmed by an intrinsic reaction coordinate calculation. This minimum lies $1.2 \mathrm{kcal} \mathrm{mol}^{-1}$ higher in energy than $\left(\mathrm{S}_{0}\right)$-Min. From the diazomethane minimum, the reaction proceeds further with cleavage of the second $\mathrm{CN}$ bond to yield the carbene. The second $\mathrm{C}-\mathrm{N}$ cleavage has a barrier of $26.5 \mathrm{kcal} \mathrm{mol}^{-1}$, similar to the barrier of 34.0 obtained at the RI-CC2 level. ${ }^{32}$

The calculated reaction barriers for the six derivatives measured in ref. 8 are presented in Table 3 and the Hammett correlations in Fig. $4 \mathrm{a}$ and b. The structures are presented in Fig. ESI1-ESI6, ESI. $\dagger$ In the vacuum, the barriers range from $3.8 \mathrm{kcal} \mathrm{mol}^{-1}$ for the most electron withdrawing $\mathrm{CF}_{3}$ substituent to $5.9 \mathrm{kcal} \mathrm{mol}^{-1}$ for the best electron donor, $\mathrm{CH}_{3} \mathrm{O}$. There is a good correlation between the calculated barriers and the $\sigma^{+}$ Hammett constants $\left(R^{2}=0.96\right)$. In acetonitrile solution, the barriers are raised by $0.1-0.5 \mathrm{kcal} \mathrm{mol}^{-1}$, and the correlation between the calculated barriers and the $\sigma^{+}$Hammett constants is maintained $\left(R^{2}=0.97\right)$. There is also a good correlation $\left(R^{2}=0.98\right)$ between the calculated barriers and the logarithm of the experimental $S_{1}$ lifetimes, $\log (\tau)$ (see Fig. $4 \mathrm{~b}$ ). The increase in the calculated barriers from the vacuum to the polar acetonitrile solvent is also consistent with the increase of the $S_{1}$ lifetimes observed experimentally with increasing solvent polarity, going from cyclohexane to chloroform and acetonitrile. ${ }^{31}$

This behaviour can be understood examining the atomic charges at the critical points. To measure the charge transfer from the phenyl ring to the diazirine moiety induced by the excitation, we have calculated the difference between the atomic charges at $\left(\mathrm{S}_{0}\right)$-Min and $\left(\mathrm{S}_{1}\right)$-Min $\left(\Delta q^{\mathrm{Min}}\right.$ in Table 3$)$ and between $\left(\mathrm{S}_{0}\right)$-Min and $\left(\mathrm{S}_{1}\right)$-TS $\left(\Delta q^{\mathrm{TS}}\right)$. The charges have been obtained from Mulliken and real-space TFVC analyses ${ }^{49}$ (see Computational details section.) They indicate that the excitation induces a substantial transfer of negative charge from the phenyl ring to the diazirine moiety at $\left(\mathrm{S}_{1}\right)$-Min, of -0.16 to -0.18 electrons (Mulliken charges at $\Delta q^{\text {Min }}$ in Table 3).
However, during the first $\mathrm{C}-\mathrm{N}$ cleavage there is a partial reverse transfer, and the relative charge transfer, $\Delta q^{\mathrm{TS}}$, is reduced to -0.08 and -0.09 . This trend is confirmed by the TFVC analysis, although this method gives a higher amount of charge transfer compared to the Mulliken analysis, both at $\left(\mathrm{S}_{1}\right)$-Min $(-0.25$ to $-0.26)$ and $\left(S_{1}\right)$-TS $(-0.19)$. However, the reverse charge transfer at the TS is also observed with the real-space partition analysis, which validates this mechanistic feature.

The reverse charge transfer increases gradually along the path to $\left(\mathrm{S}_{1} / \mathrm{S}_{0}\right)-\mathrm{X}$, where there is a net transfer of positive charge compared to the ground state (see Table ESI2, ESI $\dagger$ ). The initial transfer of negative charge and its reversal along the $\mathrm{C}-\mathrm{N}$ cleavage path is consistent with the two trends that correlate the reactivity with the electron-donating capacity of the substituents and the solvent polarity. Electron donating substituents stabilize $\left(\mathrm{S}_{1}\right)$-Min, but the stabilizing effect is lost during the $\mathrm{C}-\mathrm{N}$ cleavage because of the reverse charge transfer. This explains the higher barriers found with electron donating substituents. In addition, the $\mathrm{S}_{1}$ state has a higher dipole moment at the intact minimum than at the $\mathrm{C}-\mathrm{N}$ broken structures, which explains the stabilization of the reactant and the increase of the barrier with increasing solvent polarity, or going from vacuum to acetonitrile. Our calculated energies are consistent with both trends.

The activated $\mathrm{C}-\mathrm{N}$ cleavage path is also consistent with the experimental $S_{1}$ life times of $11-760$ ps measured in acetonitrile. After excitation, $\left(S_{1}\right)$-Min carries an excess energy approximately equal to the difference between the excitation energy and the $\left(\mathrm{S}_{1}\right)$-Min potential energy. Initially this excess energy will be accumulated in the two $\mathrm{C}-\mathrm{N}$ stretch modes activated during the excitation. However, the excess excitation energy is of similar magnitude to the barrier at the TS (see Table ESI11, ESI $\dagger$ ). Therefore, cleavage of a single $\mathrm{C}-\mathrm{N}$ bond requires intramolecular vibrational energy redistribution from the two bonds to a single one, so that $\left(\mathrm{S}_{1}\right)$-Min has enough time to equilibrate vibrationally before the cleavage. This is reflected in the $S_{1}$ life times. Under these conditions, the rates follow, approximately, standard transition state theory, and the Hammett correlation can be observed. 


\section{Conclusions}

Quantum chemical calculations have allowed us to rationalize the different reactivity found for ACDA derivatives in the ground and excited states. The ground-state nitrogen elimination reaction can be understood as a reverse cycloaddition with small charge transfer from the aromatic ring. In contrast, the excited-state elimination is stepwise and starts with cleavage of a single $\mathrm{C}-\mathrm{N}$ bond to yield a diazomethane intermediate. This step is characterized by an initial charge transfer from the ring to the diazirine group which is reversed during the cleavage. As a result, the barrier for photolysis increases with a higher electron donating capability of the ring substituents. This is in agreement with the trend of the rates measured experimentally. While the reactivity trends can be explained from straightforward orbital and Mulliken charge analyses, the ACDA system appears as a good test ground for more sophisticated reactivity descriptors because consistent sets of data are available both for the ground and the excited state.

Our calculations also show that the Hammett behaviour in the excited state follows the usual scheme from ground-state reactions, i.e. the different reaction rates are due to differential stabilization of the TS by substitution of the aromatic ring. This implies that the reaction follows traditional transition state theory, which means that the excited-state minimum is sufficiently long lived to be thermally equilibrated. The question that remains open is whether excited-state processes in the subps scale, which may not necessarily obey transition state theory, can also show a Hammett behaviour. This may be the case, for instance, if the excited-state decay takes place at a conical intersection and the intersection energy is modulated by the substituent. This would be a further extension of the applicability of the Hammett approach which appears as an interesting direction for future studies.

\section{Conflicts of interest}

There are no conflicts to declare.

\section{Acknowledgements}

We thank Dr Pedro Salvador (Universitat de Girona) for help with the TFVC analysis. We acknowledge financial support from the National Natural Science Foundation of China (grants 21773007 and 21303007 for QL); the Spanish Ministerio de Economía y Competitividad (Grants RYC-2011-09582 for AM and CTQ-2015-69363-P for LB); and the Departament d'Innovació, Universitats i Empresa (DIUE), Generalitat de Catalunya (Xarxa de Referència en Química Teòrica i Computacional).

\section{References}

1 F. Plasser, A. J. Aquino, W. L. Hase and H. Lischka, J. Phys. Chem. A, 2012, 116, 11151-11160.

2 S. A. Bäppler, F. Plasser, M. Wormit and A. Dreuw, Phys. Rev. A: At., Mol., Opt. Phys., 2014, 90, 052521.
3 S. Jenkins, L. Blancafort, S. R. Kirk and M. J. Bearpark, Phys. Chem. Chem. Phys., 2014, 16, 7115-7126.

4 R. L. Martin, J. Chem. Phys., 2003, 118, 4775-4777.

5 D. Casanova and A. I. Krylov, J. Chem. Phys., 2016, 144, 014102.

6 M. Rosenberg, C. Dahlstrand, K. Kilsa and H. Ottosson, Chem. Rev., 2014, 114, 5379-5425.

7 K. A. Kistler and S. Matsika, J. Phys. Chem. A, 2007, 111, 8708-8716.

8 X. Zhang, L.-X. Ma and X.-D. Li, Synth. Met., 2014, 198, 357-360.

9 I. K. Petrushenko and K. B. Petrushenko, Spectrochim. Acta, Part A, 2015, 138, 623-627.

10 A. Harriman and R. J. Hosie, J. Chem. Soc., Faraday Trans., 1981, 77, 1695-1702.

11 P. J. Wagner, R. J. Truman and J. C. Scaiano, J. Am. Chem. Soc., 1985, 107, 7093-7097.

12 M. Sakamoto, X. C. Cai, M. Hara, M. Fujitsuka and T. Majima, J. Phys. Chem. A, 2005, 109, 4657-4661.

13 R. S. Givens and B. Matuszewski, J. Am. Chem. Soc., 1984, 106, 6860-6861.

14 M. T. H. Liu and K. Toriyama, Can. J. Chem., 1972, 50, 3009-3016. 15 Y. L. Zhang, L. Wang, R. A. Moss and M. S. Platz, J. Am. Chem. Soc., 2009, 131, 16652-16653.

16 J. March, Advanced Organic Chemistry: Reactions, Mechanisms, and Structure, John Wiley \& Sons, New York, 3rd edn, 1985.

17 R. A. Moss, Acc. Chem. Res., 2006, 39, 267-272.

18 B. Raimer and T. Lindel, Chemistry, 2013, 19, 6551-6555.

19 R. Bonneau and M. T. H. Liu, J. Am. Chem. Soc., 1996, 118, 7229-7230.

20 M. S. Platz, J. Org. Chem., 2014, 79, 2341-2353.

21 J. Peon, D. Polshakov and B. Kohler, J. Am. Chem. Soc., 2002, 124, 6428-6438.

22 J. Wang, G. Burdzinski, J. Kubicki and M. S. Platz, J. Am. Chem. Soc., 2008, 130, 11195-11209.

23 J. Wang, J. Kubicki, T. L. Gustafson and M. S. Platz, J. Am. Chem. Soc., 2008, 130, 2304-2313.

24 J. Wang, G. Burdzinski, J. Kubicki, M. S. Platz, R. A. Moss, X. L. Fu, P. Piotrowiak and M. Myahkostupov, J. Am. Chem. Soc., 2006, 128, 16446-16447.

25 Y. L. Zhang, G. Burdzinski, J. Kubicki and M. S. Platz, J. Am. Chem. Soc., 2008, 130, 16134-16135.

26 Y. L. Zhang, G. Burdzinski, J. Kubicki, S. Vyas, C. M. Hadad, M. Sliwa, O. Poizat, G. Buntinx and M. S. Platz, J. Am. Chem. Soc., 2009, 131, 13784-13790.

27 J. Wang, G. Burdzinski, T. L. Gustafson and M. S. Platz, J. Org. Chem., 2006, 71, 6221-6228.

28 J. Wang, G. Burdzinski, T. L. Gustafson and M. S. Platz, J. Am. Chem. Soc., 2007, 129, 2597-2606.

29 J. Wang, J. Kubicki, E. F. Hilinski, S. L. Mecklenburg, T. L. Gustafson and M. S. Platz, J. Am. Chem. Soc., 2007, 129, 13683-13690.

30 R. Bonneau, M. T. H. Liu, K. C. Kim and J. L. Goodman, J. Am. Chem. Soc., 1996, 118, 3829-3837.

31 M. Nigam, M. S. Platz, B. M. Showalter, J. P. Toscano, R. Johnson, S. C. Abbot and M. M. Kirchhoff, J. Am. Chem. Soc., 1998, 120, 8055-8059. 
32 Y. L. Zhang, S. Vyas, C. M. Hadad and M. S. Platz, J. Phys. Chem. A, 2010, 114, 5902-5912.

33 P. L. Müller-Remmers and K. Jug, J. Am. Chem. Soc., 1985, 107, 7275-7284.

34 F. Bernardi, M. Olivucci, M. A. Robb, T. Vreven and J. Soto, J. Org. Chem., 2000, 65, 7847-7857.

35 R. R. Pandey, Y. G. Khait and M. R. Hoffmann, J. Phys. Chem. A, 2004, 108, 3119-3124.

36 I. Fedorov, L. Koziol, A. K. Mollner, A. I. Krylov and H. Reisler, J. Phys. Chem. A, 2009, 113, 7412-7421.

37 D. S. Ahn, S. Y. Kim, G. I. Lim, S. Lee, Y. S. Choi and S. K. Kim, Angew. Chem., Int. Ed., 2010, 49, 1244-1247.

38 R. M. Mokambe, Y. G. Khait and M. R. Hoffmann, J. Phys. Chem. A, 2010, 114, 8119-8125.

39 F. Pfeiffer and G. Rauhut, J. Phys. Chem. A, 2011, 115, 11050-11056.

40 A. E. Keating, M. A. Garcia-Garibay and K. N. Houk, J. Am. Chem. Soc., 1997, 119, 10805-10809.

41 J. F. Arenas, I. López-Tocón, J. C. Otero and J. Soto, J. Am. Chem. Soc., 2002, 124, 1728-1735.

42 M. J. Frisch, G. W. Trucks, H. B. Schlegel, G. E. Scuseria, M. A. Robb, J. R. Cheeseman, J. A. Montgomery, Jr., T. Vreven, K. N. Kudin, J. C. Burant, J. M. Millam, S. S. Iyengar, J. Tomasi, V. Barone, B. Mennucci, M. Cossi, G. Scalmani, N. Rega, G. A. Petersson, H. Nakatsuji, M. Hada, M. Ehara, K. Toyota, R. Fukuda, J. Hasegawa, M. Ishida, T. Nakajima, Y. Honda, O. Kitao, H. Nakai, M. Klene, X. Li, J. E. Knox, H. P. Hratchian, J. B. Cross, V. Bakken, C. Adamo, J. Jaramillo, R. Gomperts, R. E. Stratmann, O. Yazyev, A. J. Austin, R. Cammi, C. Pomelli, J. W. Ochterski, P. Y. Ayala, K. Morokuma, G. A. Voth, P. Salvador, J. J. Dannenberg, V. G. Zakrzewski, S. Dapprich, A. D. Daniels, M. C. Strain, O. Farkas, D. K. Malick, A. D. Rabuck, K. Raghavachari, J. B. Foresman, J. V. Ortiz, Q. Cui, A. G. Baboul, S. Clifford, J. Cioslowski, B. B. Stefanov, G. Liu, A. Liashenko, P. Piskorz, I. Komaromi, R. L. Martin, D. J. Fox, T. Keith, M. A. Al-Laham, C. Y. Peng, A. Nanayakkara, M. Challacombe, P. M. W. Gill, B. Johnson, W. Chen, M. W. Wong, C. Gonzalez and J. A. Pople, Gaussian 03 Rev. E1, Gaussian, Inc., Wallingford CT, 2004.

43 M. J. Frisch, G. W. Trucks, H. B. Schlegel, G. E. Scuseria, M. A. Robb, J. R. Cheeseman, G. Scalmani, V. Barone, B. Mennucci, G. A. Petersson, H. Nakatsuji, M. Caricato,
X. Li, H. P. Hratchian, A. F. Izmaylov, J. Bloino, G. Zheng, J. L. Sonnenberg, M. Hada, M. Ehara, K. Toyota, R. Fukuda, J. Hasegawa, M. Ishida, T. Nakajima, Y. Honda, O. Kitao, H. Nakai, T. Vreven, J. A. Montgomery, Jr., J. E. Peralta, F. Ogliaro, M. Bearpark, J. J. Heyd, E. Brothers, K. N. Kudin, V. N. Staroverov, T. Keith, R. Kobayashi, J. Normand, K. Raghavachari, A. Rendell, J. C. Burant, S. S. Iyengar, J. Tomasi, M. Cossi, N. Rega, J. M. Millam, M. Klene, J. E. Knox, J. B. Cross, V. Bakken, C. Adamo, J. Jaramillo, R. Gomperts, R. E. Stratmann, O. Yazyev, A. J. Austin, R. Cammi, C. Pomelli, J. W. Ochterski, R. L. Martin, K. Morokuma, V. G. Zakrzewski, G. A. Voth, P. Salvador, J. J. Dannenberg, S. Dapprich, A. D. Daniels, O. Farkas, J. B. Foresman, J. V. Ortiz, J. Cioslowski and D. J. Fox, Gaussian 09 Rev. D1, Gaussian, Inc., Wallingford CT, 2013. 44 F. Aquilante, L. De Vico, N. Ferré, G. Ghigo, P.-Å. Malmqvist, P. Neogrady, T. B. Pedersen, M. Pitonak, M. Reiher, B. O. Roos, L. Serrano-Andrés, M. Urban, V. Veryazov and R. Lindh, J. Comput. Chem., 2010, 31, 224-247.

45 G. Ghigo, B. O. Roos and P.-Å. Malmqvist, Chem. Phys. Lett., 2004, 396, 142-149.

46 N. Forsberg and P.-Å. Malmqvist, Chem. Phys. Lett., 1997, 274, 196-204.

47 N. Yamamoto, T. Vreven, M. A. Robb, M. J. Frisch and H. B. Schlegel, Chem. Phys. Lett., 1996, 250, 373-378.

48 V. Barone and M. Cossi, J. Phys. Chem. A, 1998, 102, 1995-2001. 49 P. Salvador and E. Ramos-Cordoba, J. Chem. Phys., 2013, 139, 071103.

50 R. F. W. Bader, Atoms in Molecules: A Quantum Theory, Oxford University Press, Oxford, 1990.

51 L. A. Zapata, S. López, P. Ruiz, J. Quijano and R. Notario, Struct. Chem., 2016, 28, 597-605.

52 Q. Li, A. Migani and L. Blancafort, J. Phys. Chem. Lett., 2012, 3, 1056-1061.

53 H. Li, A. Migani, L. Blancafort, Q. Li and Z. Li, Phys. Chem. Chem. Phys., 2016, 18, 30785-30793.

54 X.-L. Peng, W.-L. Ding, Q.-S. Li and Z.-S. Li, Org. Chem. Front., 2017, 4, 1153-1161.

55 J. Ghosh, S. Banerjee and A. Bhattacharya, Chem. Phys., 2017, 494, 78-89.

56 C. Hansch, A. Leo and R. W. Taft, Chem. Rev., 1991, 91, 165-195.

57 L. P. Hammett, Chem. Rev., 1935, 17, 125-136. 